\title{
A Política Externa do Brasil no Século XXI: Os Eixos Combinados de Cooperação Horizontal e Vertical
}

\author{
Brazil's Foreign Policy in the 21st Century: The Combining Axis \\ of Horizontal and Vertical Multilateral Cooperation
}

CRISTINA SOREANU PECEQUILO*

Rev. Bras. Polít. Int. 51 (2): 136-153 [2008]

\section{Introdução}

Durante as duas as últimas duas décadas, a natureza das prioridades e perspectivas da política externa brasileira vem sendo objeto de um debate intenso. Iniciado com o fim da Guerra Fria em 1989, este debate está enraizado nas tradições das Relações Internacionais do país, opondo duas tendências: a hemisférica-bilateral e a global-multilateral. ${ }^{1}$

Porvezes polarizada, esta discussão se desenvolve em torno do questionamento das opções do governo Lula por grupos que defendem a reconstrução de uma relação especial com os EUA, em oposição a uma suposta separação que teria se instalado entre os parceiros devido às aproximaçōes buscadas com as naçōes emergentes e países menos desenvolvidos na África, Ásia, Oriente Médio e América do Sul.

Todavia, este é um debate enganoso, uma vez que o governo Lula e sua equipe de política externa, liderada por Celso Amorim à frente do Ministério das Relações Exteriores (MRE) e Samuel Pinheiro Guimarães na Secretaria-Geral do MRE, tem focado a agenda brasileira na combinação dos eixos horizontal e vertical. Inclusive, o poder de barganha frente ao eixo vertical e aos EUA tem se mostrado crescente. A política externa do século XXI transforma e atualiza o passado ao mesclar equilibradamente as dimensões Norte-Sul e Sul-Sul. Porém, esta não é uma tarefa fácil, sendo necessário examinar as décadas de $1990 \mathrm{e}$ 2000, a fim de melhor entender as perspectivas deste quadro paradigmático e as parcerias estratégicas desenvolvidas.

* Professora de Relações Internacionais da Universidade Estadual Paulista - UNESP e Pesquisadora Associada do Núcleo de Estratégia e Relações Internacionais da Universidade Federal do Rio Grande do Sul - NERINTUFRGS (crispece@gmail.com).

1 Para a história das Relações Internacionais do Brasil ver a obra clássica CERVO e BUENO, 2002. 


\section{A Década "Bilateral": Os Anos 1990}

Depois do fim da Guerra Fria, a maioria dos países, incluindo os EUA, a única superpotência restante, encontrava-se pressionada para ajustar sua agenda de política externa a um novo cenário que emergia sob o signo da cooperação e da universalização dos regimes políticos e econômicos liberais. As visões que embasavam estas avaliações eram relacionadas à criação de uma "Nova ordem mundial" sustentada na liderança dos EUA e na governança multilateral, na qual se destacava o papel mediador das Nações Unidas (ONU), e a premissa do "fim da história”. Em tal cenário de otimismo, a situação do Terceiro Mundo caminhava no sentido oposto, o do aumento da vulnerabilidade devido ao aprofundamento das crises sociais e econômicas que emergiram nos anos 1980, as transições do autoritarismo à democracia, culminando com a perda de suas táticas pendulares entre Leste e Oeste e das articulações do Movimento Não-Alinhado.

Na América Latina, este processo foi conhecido como a "Década perdida". Mesmo o Brasil, que desenvolvera sua agenda autônoma e consolidara sua potência não escaparia deste destino: hiperinflação, estagnação, instabilidade, pressões da comunidade internacional nos "novos temas" meio ambiente, proliferação e direitos humanos. Frente a estes desafios internos e externos, a pergunta que surgia era como superar a crise e se reenquadrar. Tal pergunta gerou fissuras no debate doméstico sobre qual seria o caminho mais adequado a seguir: alguns argumentavam que era preciso retomar o eixo bilateral-hemisférico, devido à supremacia dos EUA, aderindo o país aos padróes sócio, políticos e econômicos do pós-Guerra Fria, enquanto isso, outros sugeriam a correção de rumos da postura global-multilateral.

No início dos anos 90, a primeira destas visões prevaleceu. Por trás desta ação, a lógica era sustentada em dois pilares: o primeiro defendia que com o fim da bipolaridade o cenário tornara-se unipolar. Portanto, se o Brasil desejasse participar desta "nova ordem" a proximidade com os EUA era prioritária, o que nos leva ao segundo pilar, à avaliação de que as agendas prévias foram deficientes em promover este intercâmbio, levando ao isolamento ("autonomia pela exclusão" $)^{2}$ frente o Primeiro Mundo.

Devido a suas escolhas, o país entrara em uma crise que somente seria superada com a recuperação da credibilidade por meio da adequação aos fluxos do novo sistema ("autonomia pela integração") ${ }^{3}$. Tal integração era representada pela adesão às reformas políticas e econômicas patrocinadas pelos EUA e que encontravam respaldo nas organizações multilaterais como a ONU e nas negociações comerciais no âmbito do Acordo Geral de Comércio e Tarifas (Gatt). Um dos símbolos deste período foram as prescrições neoliberais do Consenso de Washington (privatização, diminuição do Estado, abertura, desregulamentação).

2 VIGEVANI e OLIVEIRA, 2003.

3 VIGEVANI e OLIVEIRA, 2003. 
O Brasil também passou a ser percebido como uma nação periférica, com opções limitadas, devendo se reinserir a partir de uma relação privilegiada com os EUA. Nacionalmente, esta postura foi mediada, mas em outros países as escolhas recaíram no completo alinhamento. O "tipo ideal" foi a Argentina de Carlos Menem, seguida de perto pelo México de Carlos Salinas, e sua prática do "Realismo Periférico" e do "Estado Normal"4. Todavia, independente de seu comportamento mais equilibrado, o Brasil não escapou do processo de "normalização". Para superar a "Década perdida", a resposta escolhida foi a "Década bilateral".

O governo que iniciou este processo foi o de Fernando Collor de Mello (1990/1992), primeiro presidente eleito democraticamente depois do fim do regime militar. Aproveitando o cenário de profunda crise, Collor construiu sua campanha em tons populistas, propagando a imagem da mudança e modernidade que levariam o Brasil ao Primeiro Mundo. A implementação do Consenso de Washington e a assinatura de diversos regimes internacionais foram as prioridades.

Além das consequências político-econômicas, um efeito adicional foi o desmonte do projeto de segurança nacional ${ }^{5}$. Durante quase uma década as Forças Armadas foram colocadas como baixa prioridade. Esta situação somente começou a mudar em 1998 com a criação do Ministério da Defesa no governo de Fernando Henrique Cardoso (FHC) dando-se início a discussões mais substantivas sobre uma política de defesa, a questão das relaçóes civis-militares e o reaparelhamento das Forças Armadas (temas que permanecem como desafios na administração Lula).

A base destas opçóes era promover o realinhamento com os EUA e demais países desenvolvidos por meio do incremento da credibilidade pela adesão aos valores do pós-Guerra Fria. ${ }^{6}$ Em contrapartida, os países em desenvolvimento receberiam reconhecimento político, concessões comerciais e ajuda financeira e tecnológica do eixo vertical. A despeito do engajamento, o Brasil recebeu poucos benefícios. Apesar da promessa de superar a crise, a administração promoveu medidas impopulares e sem efeito, como o congelamento da poupança. O cenário tornou-se mais instável quando o presidente, e seus principais assessores foram acusados de corrupção, que levou ao impeachment em 1992.

Como prova do amadurecimento democrático, o vice-presidente Itamar Franco assumiu o poder e tentou, em um contexto bastante sensível, estabilizar o país e minimizar os efeitos negativos das escolhas de Collor. Na política externa, Franco deu continuidade ao Mercosul, projeto de integração regional no Cone Sul implementado por seu antecessor, que possuía conteúdo tanto de autonomia quanto de alinhamento.

4 CERVO e BUENO, 2002.

5 CERVO e BUENO, 2002.

6 Para uma visão positiva da agenda de Collor, LAFER, 2003, e para os críticos BATISTA, 2003. Para Collor e Itamar, HIRST e PINHEIRO, 1995. 
No que se refere à autonomia observa-se a continuidade da "sul-americanização" da agenda regional que se iniciara nos anos 70 (regime militar) e que ganhara impulso na década seguinte (Sarney e Alfonsin), visando explorar a complementaridade econômica e proximidade político-estratégica no Cone Sul (Argentina). Esta solidez da plataforma continental era percebida como essencial para o fortalecimento regional e nacional em meio à vulnerabilidade.

A dimensão do alinhamento corresponde à aceleração do processo de integração por Collor nos anos 1990, acompanhada por Menem na Argentina, e que passou a incluir Uruguai e Paraguai. O Mercosul, e o conteúdo das políticas nacionais de seus membros, demonstravam-se alinhadas às reformas do Consenso de Washington e aos EUA. Inclusive, os EUA apresentavam seus projetos de integração regional: a Iniciativa para as Américas (IA), o Nafta (Acordo de Livre Comércio entre EUA, Canadá e México), em vigor desde 1994, e a Área de Livre Comércio das Américas (Alca), lançada neste mesmo ano, com previsão de conclusão de negociações até 2005, até hoje sem definição. ${ }^{7}$

Em Itamar, novas abordagens foram desenvolvidas, que distanciavam a agenda do eixo vertical, retomando parcerias horizontais. O objetivo de alcançar reconhecimento político teve o foco deslocado da aquiescência para um incremento de participação, em particular na ONU, tendo como base a defesa da reforma do Conselho de Segurança e a candidatura brasileira a um assento permanente.

Em 1995, este redirecionamento sofreu uma nova alternância quando Franco foi sucedido por FHC, que havia sido seu Ministro das Relações Exteriores e, mais importante, Ministro da Fazenda, sendo responsável pela implementação do Plano Real em 94. FHC permaneceu no poder até 2002, sendo reeleito em 1998. Na história dos programas de estabilização econômica nacionais, o Plano Real foi bastante bem sucedido, colocando fim à crise, ainda sustentado nas reformas neoliberais. A retomada da "Década bilateral" não representou uma intensificação do quase automatismo de Collor. Permanecia a busca pela credibilidade só que matizada por uma postura pragmática, a criação de uma imagem positiva e críticas moderadas à"globalização assimétrica", como sustenta Vizentini (2003). Na gestão Cardoso, o MRE ficou sob a responsabilidade de Luiz Felipe Lampreia (1995/2002) e Celso Lafer (2002).

Um dos marcos desta postura foi a ratificação do Tratado de NãoProliferação em 1998 e outros regimes, que somados à estabilidade econômica e política alcançadas, eram apresentados como prova da responsabilidade nacional. Segundo os cálculos governamentais, esta dinâmica levaria ao reconhecimento do país como pilar da nova ordem. Estas contribuições positivas, que substituíam a barganha, garantiriam uma espécie de "bilhete de entrada para o Norte" e a realização dos propósitos nacionais. Os principais objetivos? Comércio livre e

7 Ambas as visões são encontradas em PECEQUILO, 2005, VIZENTINI, 2003. 
justo nas negociações da OMC e da Alca e um assento permanente no CSONU. Os objetivos alcançados? Nenhum.

$\mathrm{Na} \mathrm{ONU}$, a reivindicação por assento permanente no CS, que nascera no governo Itamar, associada à reforma ampla da instituição, ganhou maior evidência em $95,50^{\circ}$ aniversário da organização. Depois de algumas rodadas de consulta, as propostas de atualização (apresentadas desde 1989) foram colocadas de lado a despeito do claro descompasso entre a OIG e a realidade do novo sistema, principalmente no que se refere à participação de novas nações desenvolvidas e emergentes no $\mathrm{CS}^{8}$. A opção brasileira de agir isoladamente pelos "ganhos de credibilidade" não produziu apoios (situação corrigida pela administração Lula que buscou uma tática diferenciada). Não existiram mudanças, situação que se repetiu na OMC.

Desde 1995, as negociações da OMC tem aprofundado o tradicional gap entre as posições do Primeiro e do Terceiro Mundo. Enquanto o Terceiro Mundo incrementou as pressóes para a abertura dos mercados agrícolas, depois das concessões efetuadas no setor industrial no âmbito da Rodada Uruguai do Gatt, o Primeiro apresentou uma nova proposta de liberalização nos moldes da agenda de Cingapura para a abertura de bens e serviços. Em 1999, a Rodada do Milênio deixou bastante clara esta paralisia e o crescimento dos movimentos antiglobalização e suas alianças instrumentais com grupos protecionistas nos países desenvolvidos. A violência dos protestos em Seattle e a ausência de resultados colocou em xeque o futuro da OMC. Porém, em 2001, em Doha, a Rodada do Desenvolvimento veio a substituir a do Milênio.

Realizada sob a sombra dos atentados de 11 de setembro aos EUA, Doha foi caracterizada por uma relativa boa vontade norte-americana em lançar o processo negociador, visando capitalizar apoio para a Guerra Global contra o Terror (GWT). As negociações da OMC, associadas à operação empreendida no Afeganistão (2001), foram utilizadas pela presidência George W. Bush, que tomara posse em janeiro daquele ano, e pendia ao unilateralismo, como uma demonstração de que não havia abandonado o multilateralismo. O "viés multilateral" foi breve, e somente no segundo mandato (2005 em diante) poderá ser observado uma tentativa de matizar estas ações devido às crises geradas pela Doutrina Bush (2002) ${ }^{9}$ e Guerra do Iraque (2003). Em Doha, mais uma vez, os resultados foram escassos.

O impacto deste processo paralisado e a ausência de concessóes norteamericanas levou o governo de FHC a abrir uma série de contenciosos conta os EUA na OMC, já tendo sido conquistadas diversas vitórias em painéis referentes à soja e algodão, somente para citar alguns. Apesar disso, os EUA não mudaram suas políticas nestes e outros pontos de atrito no comércio bilateral. Situação

8 Ver LAMPREIA, 1999.

9 PECEQUILO, 2005. 
similar se repetiu com as nações européias, em suas políticas individuais e comuns, o que demonstrou as limitações do eixo norte das parcerias estratégicas a despeito do processo de readaptação realizado.

A mesma dinâmica marcou as negociações da Alca, processo de integração controverso tanto nos EUA como no Brasil. Apesar das tentativas de criar formatos "light" para o arranjo, não se conseguiu gerar um consenso que desse conta de seus desafios, das obstaculizadas negociações da OMC, dos interesses domésticos dos EUA e da conciliação com acordos regionais pré-existentes (Nafta e Mercosul).

Diante destes limites, a "Década Bilateral" começava a dar sinais de esgotamento, que revelavam uma certa frustração do Brasil e outros países. Mais do que isso, dez anos de ajustes políticos e econômicos profundos trouxeram um cenário de crise para a América Latina. Tal cenário variou de intensidade em cada nação, dependendo de uma outra intensidade: a da aplicação do receituário de normalização. Argentina, México, Bolívia, Equador, dentre os mais alinhados, sofreram a exacerbação de problemas sociais e econômicos, culminando em fragmentação política e rupturas institucionais. Países como o Brasil que matizaram a agenda neoliberal passaram por dificuldades (estagnação, desemprego), mas sem quebra da ordem vigente. A atualização do Plano Real em 1998/1999, as oscilações cambiais, a crise do Mercosul, fazem parte do processo que levou à mudança da política externa a partir de 1999/2000.

Além disso, como mencionado, em 2001, uma nova presidência tomara posse nos EUA, com viés unilateralista, e prioridade à Eurásia (apesar das promessas de campanha de Bush do "Século das Américas" sugerirem a revitalização do intercâmbio hemisférico). No campo comercial, em detrimento do multilateralismo preferiu-se o bilateralismo ${ }^{10}$. Isto se refletiu no aprofundamento do Plano Colômbia lançado em 2000 e, pós 11 de setembro, no combate ao chamado "narcoterrorismo", a preocupação com a tríplice fronteira Brasil, Paraguai, Argentina e a instalação de bases militares na América do Sul (Paraguai). Tal situação somente se intensificou com a Doutrina Bush, distanciando ainda mais os EUA de seu continente.

Como Vizentini (2003) ressalta, FHC alterou o curso de sua política externa do eixo vertical norte para a América do Sul, reintegrando países emergentes como Rússia, China e Índia e intensificando o discurso da "globalização assimétrica". A tática foi de combater a crise do Mercosul e dos países sul-americanos a partir de dentro do continente, ampliando a integração do Cone Sul para o contexto regional. Em 2000, isto levou à Cúpula de Brasília que promoveu a criação da IIRSA (Integração da Infra-estrutura Regional Sul Americana). Por conta destas atualizaçōes, o encerramento da presidência foi marcada por críticas similares as que foram apresentadas à administração Lula. FHC passou a ser questionado

10 Um breve histórico das relações bilaterais de 1993 a 2004 pode ser encontrado em PECEQUILO e GOMES, 2004. 
quanto ao abandono da "Década bilateral" e pela correção de rumos do Estado Normal, substituído pelo Logístico no conceito de Amado Cervo ${ }^{11}$.

No governo seguinte o perfil e intensidade destas críticas seriam ainda maiores, apresentando muitas das iniciativas lançadas por FHC como "novidades", esquecendo-se da dimensão de continuidade que prevaleceu na América do Sul, nas negociaçõos da OMC e na ONU. Estas visões seriam intensificadas pelo novo estilo tático da presidência e a combinação dos eixos vertical e horizontal das Relações Internacionais.

\section{Os Eixos Combinados (2003-2008)}

Depois de vários anos de perda de poder de barganha, capacidade estatal, autonomia e a ocorrência de crises políticas e econômicas na maioria dos países da América Latina, a região passou a rever suas prioridades. Nas palavras de Castañeda (2006), a América Latina fez "uma curva à esquerda" no início do século XXI, caracterizada por duas diferentes opções: Venezuela e Brasil. Para Castañeda, Brasil, Chile (Bachelet), Uruguai (Vasquéz), representam uma esquerda pragmática e centrista que buscou a correção das políticas prévias a partir de uma abordagem incrementalista que atualizava os laços com a comunidade internacional e o reordenamento dos objetivos internos em um ambiente de cooperação e gradualismo.

Em oposição, a Venezuela de Hugo Chavéz buscou um caminho de contestação aberta à agenda vigente, alianças com Estados definidos como "bandidos" pela diplomacia dos EUA como Cuba e Irã e a promoção do socialismo do século XXI. Ao lado de Chavéz, aliados como Rafael Correa e Evo Morales tornaram-se presidentes de Equador e Bolívia com retórica e prática similar. Em países como Peru e México, Ollanta Humalla e Lopéz Obrador não ganharam as eleiçōes presidenciais, mas ameaçaram de perto os candidatos vencedores, Alan Garcia e Felipe Calderon. Parafraseando Castañeda, enquanto a esquerda moderada é definida como "responsável", a chavista seria "irresponsável".

Embora seja possível concordar com esta análise quanto ao potencial de polarização representado por Chavéz é preciso procurar entender o contexto que permitiu a expansão destas forças: fragmentação social e crises recorrentes. $\mathrm{Na}$ realidade, estas abordagens táticas diversas possuem objetivos similares: a reforma do neoliberalismo e do Estado e a projeção de uma postura autônoma no cenário externo.

A dinâmica de divergência e convergência entre os projetos de esquerda pode ser vista na relação bilateral entre Brasil e Venezuela. Em comum, ambos os países buscam uma atualização de suas agendas e a recuperação de espaço. $\mathrm{Na}$ América do Sul, o discurso consensual é acompanhado por projetos distintos, a

11 CERVO e BUENO, 2002. 
despeito de suas complementaridades: a CASA (Comunidade Sul-Americana de Naçōes, hoje Unasul, Uniāo Sul-Americana de Naçôes) liderada pelo Brasil e a Alba (Alternativa Bolivariana para as Américas) proposta por Chavéz. Outros ponto de tensão referem-se à preservação do relacionamento bilateral entre EUA e Brasil em bons termos e o tema da energia, setor no quais os interesses brasileiros chocaram-se com os bolivianos e também com os venezuelanos no campo do gás, petróleo e biocombustíveis.

Mesmo Lula, durante a campanha eleitoral era visto como um "perigo", devido ao que Vizentini define como o temor de "uma mudança brusca e uma postura ideológica militante"12. Como o autor lembra, estes temores somente foram abandonados pela comunidade internacional, principalmente pelos EUA, depois da indicação da equipe de governo. Com isso, foi dada continuidade ao processo de substituição do bilateralismo dos anos 1990 por uma versão atualizada do eixo global-multilateral.

Como citado, esta não tem sido uma transição fácil, principalmente no âmbito doméstico, uma vez que o debate ainda se mantém permeado por tensões ideológicas ${ }^{13}$, gerando classificaçôes como "Americanistas e Anti-Americanistas". ${ }^{14}$ Estas discussões, em particular da parte dos defensores do retorno da "Década bilateral" muitas vezes escondem o perfil da história diplomática brasileira que em inúmeras oportunidades comprovou que não existe incompatibilidade em negociar simultaneamente com os EUA, outros atores e OIGs. Da mesma forma, revelam uma certa incompreensão da tradição das Relações Internacionais estadunidenses que demonstram que o país tradicionalmente beneficia parceiros com forte poder de barganha e não os que buscam alinhamentos.

Além disso, estas críticas revelam percepçōes equivocadas sobre o Brasil (e sua suposta fraqueza), o mundo (unipolar) e as prioridades dos EUA (econômicas e direcionadas à América Latina). Portanto, para implementar sua política externa, o governo Lula vem sendo confrontado por inúmeros desafios, corrigindo padróes prévios $^{15}$. Primeiro, a percepção da fraqueza foi substituída por uma reavaliação do papel do Brasil como potência média e nação emergente que precisa de uma diplomacia de alto perfil adequada a suas capacidades e necessidades. A reafirmação dos interesses políticos e econômicos aparece ao lado de uma agenda social pós-globalizaçãó ${ }^{16}$. Nas palavras de Celso Amorim,

Temos consciência de que a afirmação dos valores e interesses brasileiros no mundo é- e sempre será- global em seu alcance. Sem entrar no mérito de saber se isso é uma vantagem ou desvantagem, o Brasil não é um país pequeno. Não tem e nem pode ter uma política externa de país pequeno (AMORIM, 2007, p. 7)

12 VIZENTINI, 2006: p. 166.

13 ALMEIDA, 2006.

14 ABDENUR, 2007.

15 VIGEVANI e CEPALUNI, 2007 indicam ser esta uma "autonomia pela diversificação".

16 VIZENTINI, 2003. 
Em segundo, o ordenamento do sistema passou a ser visto de um ponto de vista realista, transitando da uni à multipolaridade. Ainda que detenham poder incontestável no campo militar, os EUA tendem a compartilhá-lo nas demais esferas devido à intensificação dos processos de interdependência e transnacionalização por eles mesmos capitaneados. A diversificação dos pólos de poder, incluindo potências desenvolvidas e emergentes caracteriza este momento: China, Índia, Rússia, União Européia, Japão, Brasil e África do Sul são alguns destes agentes. Paradoxalmente, é interessante mencionar que a unipolaridade manteve-se associada nos EUA ao grupo neoconservador e percepções ultrapassadas, enquanto no Brasil, durante a "Década bilateral", e mesmo atualmente, esta avaliação é tomada como positiva ${ }^{17}$.

Por fim, as prioridades norte-americanas e sua posição relativa nos campos estratégicos e econômicos e sua relação com parceiros regionais foram reavaliadas: os EUA surgiam como um país hegemônico, mas pressionados econômica e estrategicamente. Apesar disso, permanecem como um relevante parceiro, reconhecendo-se a necessidade de incrementar o poder de barganha nacional à medida que este país privilegia em negociações Estados fortes. Este padrão de auto-respeito é comum em parceiros norte-americanos como China e Índia, e passou a ser adotado pelo Brasil pela ampliação de sua agenda e conciliação do bilateralismo com seu característico perfil de global trader and player.

Entretanto, ainda existem limites práticos às concessóes que os EUA ofereceriam ao Brasil, que se referem a uma realidade geopolítica particular. Tanto Índia quanto China localizam-se na Eurásia, uma região na qual a tática da superpotência favorece um equilíbrio de poder através do qual ambas contémse mutuamente por meio de benefícios alternados que recebem dos EUA: a China possui um acesso mais facilitado aos mercados norte-americanos, enquanto a Índia assinou um tratado nuclear bilateral com os EUA, mesmo sem ser signatária do TNP.

Além disso, o Brasil, no campo estratégico-militar possui muito menor poder relativo do que as nações eurasianas. Aparte a tradição de cooperação, não confrontacionismo e preferência por instrumentos legais, associado à imagem de uma América do Sul "pacífica", estes recursos de poder, como já discutido, sofreram um importante revés na "Década Bilateral". Adicionalmente, qualquer ganho relativo no campo militar teria um impacto negativo sobre os interesses norte-americanos

Contudo, desenvolvimentos nesta área, e na avaliação do Brasil pelos EUA como um poder estabilizador, acentuaram-se devido à ascensão de Chavéz e ao vácuo de poder norte-americano acentuado pela GWT. A expansão positiva da ação brasileira na ONU com a liderança da operação de paz no Haiti, sua mediação via OEA e bilateralmente de tensões entre vizinhos como Colômbia,

17 PECEQUilO, 2005. 
Equador e Bolívia, ressaltaram desde 2003 sua importância para os EUA. Segundo a Secretária de Estado Condoleezza Rice,

(...) os EUA buscam no Brasil um parceiro regional e um líder global (...) (RICE, 2005). O Brasil vem desempenhando um papel muito positivo nos últimos eventos aqui na regiáo. Portanto, o Brasil que é uma grande democracia multiétnica deve desempenhar um papel fundamental não só nos assuntos regionais, mas nos globais (RICE, 2008).

Consideradas estas atualizações, o Brasil está reforçando as dimensões verticais e horizontais da agenda, do bi e do multilateralismo, com prioridades que retomam as ações de FHC com a introdução de novos tópicos, havendo a mudança tática do "bom comportamento" pela "barganha de" alto perfil. Segundo Vizentini,

(....) Lula começou a desenvolver uma agenda internacional intensa como porta voz de um projeto (...) uma política externa de desalinhamento em relação ao consenso do "Atlântico Norte" como forma de recuperar a capacidade de negociação."18

O eixo horizontal é representado pelas parcerias com as nações emergentes, por suas semelhanças como grandes Estados periféricos e países em desenvolvimento como Índia, China, África do Sul e a Rússia (sendo que informalmente, o Brasil, a Rússia, a Índia e a China formam o chamado bloco Bric). A agenda é composta também pelos países menos desenvolvidos (LDCs) da África, Ásia e Oriente Médio, cujo poder relativo é menor do que o brasileiro. Este eixo representa a dimensão terceiro-mundista da política externa, também definida como relações Sul-Sul. Os benefícios potenciais deste eixo são econômicos, estratégicos e políticos.

Na dimensão político-estratégica, a proximidade de objetivos entre as nações do Sul refere-se a uma reivindicação permanente desde o fim da Guerra Fria que é a da reforma das OIGs como G8, FMI, Banco Mundial e, principalmente, do CSONU. Aqui a dinâmica de alianças e coalizões é complexa e envolve não só o eixo vertical como o horizontal. No que se refere ao G8, Brasil, China, África do Sul e Índia associam-se para a promoção de um novo organismo que inclua países emergentes, completando a atualização do antigo G-7 iniciada com a inclusão da Rússia. As hipóteses giram em torno de um G-10, G-13, como uma versão de emergentes, o G-5 com Brasil, China, Índia, África do Sul e Rússia ${ }^{19}$.

Diferente da era FHC quando a tática na ONU foi solitária, o Brasil buscou articular um quadro de alianças. Além de apoios conquistados de Rússia (a quem o país apóia em seu pleito na OMC), Grã-Bretanha e China, o Brasil esteve ao lado de Japão, Alemanha e Índia em um G-4, exemplo concreto da junção

18 VIZENTINI, 2006, p. 189.

19 VIZENTINI, 2006. 
do eixo vertical e horizontal, que defendia em 2005 a reforma da ONU (60 aniversário). O G-4 posteriormente foi abandonado pelo Japão devido ao apoio explícito dos EUA a sua candidatura e a rejeição da Alemanha. Pois,

(...) a posição dos EUA sobre a reforma do CSONU é bastante conhecida (...) Há várias administrações já estamos comprometido com o Japão como um candidato apropriado para o assento de membro permanente no CS (...) O mundo mudou desde 1945 e estamos em consulta constantes com os outros membros permanentes, mas também com Estados como o Brasil e outros. Acredito que, conjuntamente, com suficiente esforço e criatividade (...) poderemos nos mover adiante (...) o Presidente tem sido bastante claro que está aberto à reforma do CS. (RICE, 2008)

Se a posição dos EUA é bastante conhecida como diz Rice, também o é a do Brasil,

É difícil prever se haverá um G-11, G-12, G-13 ou outro G. Mas duas coisas são certas. Uma é que esses mecanismos embora úteis não substituem as instâncias multilaterais formais. A outra é que não existe ordem ou governança no plano internacional sem que a maioria esmagadora da humanidade internacional participe de sua gestâo. (AMORIM, 2007, p. 19)

Em termos econômicos (e em certa medida estratégicos e diplomáticos também), estes países possuem potencial para formar uma frente unida nas OIGs (com força quantitativa pelo número e qualitativa pelo status) que levou ao aumento de seu poder de barganha no comércio, empréstimos, dívida externa, transferência de tecnologias, ajuda direta e investimentos. Entretanto, Índia, Brasil e China competem pelos mesmos mercados e concessões no Norte, que ainda pode exercitar seu maior poder para pressionar estas nações e oferecer, como mencionado, diferentes benefícios para cada uma das potências em sua tradicional tática de equilíbrio de poder e contenção mútua ("dividir para conquistar").

As exportações para os LDCs também são um campo de choque, uma vez que estes países na África e no Oriente Médio são mercados para bens de baixo e de alto valor agregado, representando, por sua vez, fonte de recursos estratégicos no campo energético e de matérias primas. A ofensiva da China na África e América Latina em busca destes bens por meio de trocas comerciais, ajuda direta e obras de infra-estrutura é exemplo deste movimento, confrontando avanços brasileiros e norte-americanos no continente.

Apesar deste elemento competitivo, o Brasil conseguiu aumentar sua presença nos mercados do Sul e estabelecer contatos mais amplos, em particular com a Índia e África do Sul, que mostra a complementaridade entre os emergentes. O estabelecimento do Ibas (G-3) que agrega Brasil, Índia e África do Sul, um fórum de diálogo de caráter Sul-Sul tem promovido o crescimento das arenas de cooperação científica, tecnológica e política. O G-3 obteve avanços 
em parcerias na área nuclear, produção de medicamentos genéricos e de combate a Aids-HIV, programas sociais (combate à fome, assistência médica, inclusão e educação), buscando acordos quadro entre o fórum e o Mercosul e outros mecanismos de integração como a União Aduaneira da África Austral (Sacu), a Associação Sul-Asiática para Cooperação Regional (Saarc) e a Comunidade para o Desenvolvimento da África Austral (Sadc) ${ }^{20}$.

Com a China a parceria tem se desenvolvido nestas dimensões de cooperação técnica e científica, havendo maiores choques na área comercial. Tais choques resultam não só da competição mencionada acima, a Norte e Sul, mas também da penetração dos produtos chineses no mercado brasileiro, que tem sofrido restrições em setores como têxteis, calçados e brinquedos.

O relacionamento Rússia-Brasil também tem crescido no eixo comercial e político, mas, comparado com as demais relações do eixo horizontal, os potenciais de intercâmbio ainda estão se desenvolvendo em menor velocidade. As razões para distanciamento referem-se à natureza da política externa russa no pósGuerra Fria, que transita entre seu passado de superpotência e sua "nova vocação" de emergente, suas divisões européias e eurasianas e o foco energético de sua estratégia. As limitações do poder russo, e sua recente recuperação, não permitem uma projeção de poder além da Eurásia na qual se concentram seus principais recursos naturais de barganha (petróleo e gás) e seus mercados consumidores (Europa Ocidental e China). As parcerias russo-chinesa possuem prioridade, simbolizadas pela Organização de Cooperação de Xangai. Para Rússia e China, estas parcerias funcionam como uma forma de contenção mútua e de pressão sobre os EUA, que busca, por sua vez, avançar na Ásia Central e na Europa Oriental, antigas esferas de influência soviética.

Mesmo assim, como Vizentini (2006) e Lima (2005) destacam, o espaço de ação brasileiro vem crescendo gradualmente, e em mais intensidade do que no eixo Norte, o que se revela também na análise de Celso Amorim,

Pegue um economista como o Albert Fishlow (da Columbia University). Em entrevista recente ele disse que o desenvolvimento dessas relações Sul-Sul é uma das razōes pelas quais o Brasil encontra-se menos vulnerável aos problemas na economia americana. Fishlow sempre defendeu a ALCA no lugar de nossas iniciativas com a China, a África, os países árabes e sobretudo com a própria América do Sul. Quando ele fala agora sobre o Brasil e a crise americana, não há a menor dúvida que optamos pelo caminho certo. Ao criarmos o G-20 acabamos por extrapolar o âmbito da Organização Mundial de Comércio (OMC). Isso nos valeu uma credibilidade enorme com os países em desenvolvimento que acaba enfim se refletindo no clima dos negócios. Entre 2003 e 2007 num contexto em que as relaçôes comerciais do Brasil cresceram como nunca, a participação dos países em desenvolvimento no montante de nossas exportações que era de $45 \%$, trocou de posição com a dois países

20 VIZENTINI, 2006. 
desenvolvidos que correspondia a 55\%. Hoje é exatamente o contrário, o que nos deu um colchão para enfrentar a crise. A maioria dos economistas está dizendo agora que a esperança de crescimento do mundo reside nos países emergentes (...) Nós tivemos a intuição- ou percepçãa- disso antes das coisas acontecerem. (Entrevista de AMORIM a PAIVA, 2008, J5)

Complementando este eixo horizontal com elevado grau de prioridade e como uma plataforma de relacionamento entre o Brasil, seus parceiros e o restante do mundo encontram-se os projetos de integração sul-americana. Desde os anos 1970, esta política sul-americana assumiu status de prioridade "primeira". Além das questôes comerciais, iniciativas como a ALCSA, IIRSA, Casa e Unasul, possuem uma dimensão política e estratégica que visa estabelecer laços que ultrapassem a livre troca de mercadorias, concentrando-se na complementaridade das economias, sua identidade cultural e problemas sociais comuns, associando a somatória de vantagens estratégicas comparativas nos setores energético, de infra-estrutura e produção de bens (industrias, agrícolas e matérias primas) ${ }^{21}$. A ampliação dos contatos extra-regionais, capitaneados pela diplomacia brasileira simbolizados no Ibas e a Cúpula dos Países Árabes e Sul-Americanos fazem parte desta agenda. Contudo, estas propostas de unidade não eliminam a existência de projetos concorrentes ao brasileiro como os apresentados pelos EUA ou Venezuela.

O outro eixo que recebe atenção é o vertical, representado pelos tradicionais intercâmbios com países do Primeiro Mundo, EUA, nações da União Européia e Japão. Tais intercâmbios correspondem a temas econômicos, estratégicos e políticos, amparados por uma clara percepção das assimetrias de poder, potenciais e obstáculos destas relaçôes. Consideradas as três áreas de oportunidade, os EUA mantém-se a principal e nosso mais importante parceiro individual. Avaliando com distanciamento a última década das relações bilaterais Brasil-EUA não existiram rupturas profundas. Se houve quebra, esta foi no debate doméstico e não entre interlocutores brasileiros e estadunidenses.

É necessário entender os limites que afetam esta relação bilateral (alguns elementos já foram explicados brevemente). Primeiro, devido ao desenvolvimento do Brasil, a agenda de política externa não pode ficar limitada ao continente americano ou aos EUA. Segundo, os EUA possuem importantes constrangimentos estruturais domésticos que dificultam a ampliação do relacionamento. Na Era Bush, estes constrangimentos emergem das opções neoconservadoras, somada à onda protecionista de longa duração comercial que domina a sociedade e o Legislativo.

Subsídios e medidas contra produtos brasileiros são reais e impedem uma expansão das exportaçōes, como indicado no documento "Barreiras a produtos brasileiros no mercado dos EUA" preparado pela Embaixada do Brasil em Washington ao lado da Funcex (2007). Tal onda é acompanhada por um

21 COSTA, 2003 
sentimento isolacionista e reflete no travamento das negociações da Alca e da OMC, impactando, negativamente, uma outra tática preferencial do governo nos últimos anos: o estabelecimento de tratados bilaterais com nações menos desenvolvidas da América Central e parceiros preferenciais na América do Sul como Chile e Colômbia que não demandam concessões.

Mesmo estes acordos de "baixo-custo" não vem sendo aprovados pelo Congresso, em particular desde 2006 quando os democratas recuperaram a maioria do Legislativo nas eleiçóes de meio de mandato. Em meio à crise, estes tratados, o livre comércio, o Nafta são apresentados como responsáveis pela desaceleração da economia, o desemprego, a inflação e o déficit, tema que dominou a campanha para o congresso e a presidência de 2008. Estas críticas emergem principalmente do partido democrata, partindo de ambos os pré-candidatos que disputavam as primárias, Hillary Clinton e Barack Obama, e foram menos presentes do lado republicano de John McCain, mas sem que haja uma posição pró-livre comércio. Positivamente, todos estes candidatos destacaram em seus discursos a relevância do Brasil como parceiro dos EUA e nação emergente. ${ }^{22}$

Estes elementos afetam duas questōes na agenda bilateral: as negociações energéticas e a Rodada de Doha. No que se refere às conversações energéticas entre 2005/2007, Brasil e EUA aproximaram-se para aprofundar sua parceria no campo dos biocombustíveis. A emergência de uma nova matriz energética, a criação de um mercado global de etanol e trocas tecnológicas foram apresentadas como uma forma de proteger o meio ambiente ("energia limpa") e diminuir a dependência do petróleo.

Estes potenciais foram contestados pelos países produtores de petróleo, incluindo a Venezuela e setores protecionistas norte-americanos que não desejam a abertura de mercado ao álcool de cana que compete com o etanol de milho dos EUA. Estas oposições tornaram-se ainda mais acirradas, passando a incluir OIGs (ONU, Banco Mundial) e a União Européia, que responsabilizaram a produção de etanol por duas crises: a ambiental e a alimentar, uma vez que o aumento da produção de cana estaria trazendo a destruição de florestas nativas e da área para o cultivo de alimentos. Ambas perspectivas são discutíveis e respondem a uma mudança na posição relativa do Brasil devido a estas vantagens energéticas, como mascaram outros fatores que geram estas crises: a produção industrial dos países desenvolvidos (EUA), a expansão da China (produção e consumo), os empecilhos à liberalização agrícola (OMC), a falência estrutural de alguns países do Terceiro Mundo (que teriam potencial para produzir seus alimentos e recursos nacionais para se tornarem auto-suficientes caso do continente africano) e a ausência de ajuda a estas nações da parte do Primeiro Mundo.

A OMC e suas negociações representam um impasse entre Brasil, EUA e o eixo vertical em geral desde sua criação como discutido. Desde 2001, as 
negociações em vigor da Rodada Doha apresentam uma dinâmica e combinação dos eixos vertical e horizontal, envolvendo a formação do G-20, a aproximação com os EUA e as interações do G-4. Como o G-3, o G-20 é exemplo de uma aliança de geometria variável criada para as negociaçóes da Rodada Doha referentes à Conferência Ministerial de Cancun em 2003. Liderada pelo Brasil, a aliança teve como objetivo impedir concessões adicionais dos países em desenvolvimento e LDCs aos países desenvolvidos no setor industrial e agenda de Cingapura sem reciprocidade na dimensão agrícola. À medida que os países desenvolvidos não aceitaram esta proposta, a reunião encontrou-se paralisada e acusações à "má-vontade" brasileira seguiram-se. Entretanto, esta paralisia pôde ser vista como uma vitória para o G-20 que continua em funcionamento (com alterações de membros). ${ }^{23}$ A despeito destas elevações de retórica, ficou claro que o processo negociador precisaria encontrar um novo ritmo, havendo uma maior interação entre EUA, Brasil, Japão e UE, uma espécie de G-4 que trouxe poucos resultados.

Estas tensões na $\mathrm{OMC}$, entretanto, não afetam negativamente a agenda político-estratégica com o eixo vertical. Pode-se dizer que houve um amadurecimento no âmbito das parcerias com EUA e UE, amparada pela sustentabilidade das parcerias ao Sul, focando-se nos progressos possíveis e não nas divergências. Como Amorim (2008) ressalta, tem existido um incremento do diálogo estratégico com a UE, mas, principalmente, com os EUA evidenciadas pelas açōes brasileiras na América do Sul, na ONU, na OMC e em questōes específicas como do Oriente Médio (nas negociações de Annapolis o Brasil foi convidado como interlocutor do processo de paz patrocinado pelos EUA).

Os potenciais dos eixos horizontal e vertical possuem significativo espaço de desenvolvimento, amparados em parcerias estratégicas clássicas com os EUA e a Europa, mas também por meio de adaptações, renovações e ampliações dos contatos ao Sul com emergentes e LDCs em todos os continentes e nas dinâmicas de alianças nas OIGs. A substituição da tática da credibilidade pela barganha permitiu este avanço, ainda que os críticos lembrem que nem a OMC foi destravada ou o Brasil conseguiu seu assento permanente na ONU. No curto prazo esta é uma avaliação correta, mas no médio e longo esconde a dinamização de mecanismos de pressão sobre estas questôes, assim como a ampliação das ações brasileiras, em particular na ONU e em seus intercâmbios estatais.

Esta coadunaçãa dos eixos tem se provado essencial para a recuperação do status como potência média emergente, permitindo revitalizar tradiçôes e encontrar um espaço diferenciado de atuação no reordenamento do pós-Guerra Fria. Portanto, não existe escolha entre o Primeiro e o Terceiro Mundo, os eixos Norte-Sul, horizontal ou vertical, mas sim a sua combinação. Como destaca Amorim,

23 VIZENTINI, 2006. 
O grande diferencial é que deixamos de lado a velha dicotomia (...): melhoramos nossas articulações com África, China, Índia- mas sem hostilizar os EUA e a União Européia que tem tido conosco um diálogo muito privilegiado (...) Por outro lado, não preciso olhar para EUA e Europa para enxergar o Oriente Médio e a África. (Entrevista de AMORIM a PAIVA, 2008, J5)

\section{Considerações Finais}

Se a década de 1990 representou o retorno do bilateral-hemisférico, o século XXI trouxe a demanda de atualização da tradição global-multilateral. Tal atualização trouxe uma evolução por meio da convergência dos níveis bi e multilateral da política externa, focando na ampliação e combinação das dimensões horizontais e verticais das parcerias estratégicas. Embora esta interação não seja inédita na história diplomática, o movimento presente dota estes intercâmbios de maior adensamento, advindo do próprio amadurecimento do país desde as origens desta agenda nos anos 60, sua intensificação e expansão na década seguinte e seu relativo encolhimento em 80. Existe, assim, um salto qualitativo neste processo, ainda em construção, e que se desenvolve a partir de uma percepção positiva do país, sua opção por uma ação de alto perfil e a realidade de um sistema que transita do uni ao possível multipolarismo.

Neste caminho, é preciso lembrar que ambas as opções podem convergir de Norte a Sul e que as Relações Internacionais brasileiras são uma função de seus potenciais internos e externos. Mais do que positiva, a oscilação horizontalvertical, até que se chegasse a esta nova versão de combinação, foi por vezes tratada não como debate necessário, mas como visões excludentes, obscurecendo uma percepção realista sobre o Brasil e o mundo. Certamente existem desafios, mas na maioria das vezes os piores obstáculos não chegam de fora, e sim de dentro.

Recebido em 28 de abril de 2008 Aprovado em 15 de setembro de 2008

\section{Referências bibliográficas}

ABDENUR, Roberto. Entrevista à revista Veja, Páginas Amarelas, 7/2/2007.

ALMEIDA, Paulo Roberto de. "Uma nova arquitetura diplomática? Interpretaçōes divergentes sobre a política externa do governo Lula (2003/2006)". Revista Brasileira de Política Internacional, 49 (1), 2006.

AMORIM, Celso. A diplomacia multilateral do Brasil - um tributo a Rui Barbosa. Brasília: Ed. FUNAG, 2007.

AMORIM, Celso. Entrevista a PAIVA, Fred Melo. "Notícias do Itamaraty”. Caderno Aliás, J4 e J5. O Estado de S Paulo, 16 de Março de 2008. 
BRASIL. Embaixada do Brasil em Washington. Barreiras a produtos brasileiros no mercado dos EUA. Embaixada do Brasil, Washington DC e Funcex. 2007. [http://www.funcex.com. br/material/estudos/Barreiras2007.pdf]. Disponibilidade 13/3/2008.

BATISTA, Paulo Nogueira. “A política externa de Collor: modernização ou retrocesso”. Política Externa, 1(4), março 1993. p. 106-135.

CASTAÑEDA, Jorge. "Latin's America turn to the left". Foreign Affairs on line [http://www. foreignaffairs.org/20060501faessay85302/jorge-g-castaneda/latin-america-s-left-turn.html].

CERVO, Amado Luiz e BUENO, Clodoaldo. História da Política Exterior do Brasil. Brasília: Ed. UnB, 2002.

CERVO, Amado Luiz. Inserção Internacional - formação dos conceitos brasileiros. São Paulo: Ed. Saraiva, 2008.

CLINTON, Hillary Rodham. "Security and Opportunity for the 21st Century". Foreign Affairs on line [http://www.foreignaffairs.org/20071101faessay86601/hillary-rodham-clinton/ security-and-opportunity-for-the-twenty-first-century.html]. Disponibilidade: 1/3/2008.

COSTA, Darc. Estratégia Nacional: A Cooperação Sul-Americana para a Inserção Internacional do Brasil. Porto Alegre, L\&PM, 2003.

GUIMARÃES, Samuel Pinheiro. Desafios Brasileiros na era dos gigantes. Rio de Janeiro: Ed. Contraponto. 2006.

HIRST, Monica e PINHEIRO, Leticia. “A política externa do Brasil em dois tempos”. Revista Brasileira de Politica Internacional, 38(1). 1995. p. 5-23

LAFER, Celso. "A política externa brasileira no governo Collor”. Política Externa, 1(4), março 1993. p. 95-105.

LAMPREIA, Luiz Felipe. Diplomacia brasileira - palavras, contextos e razóes. Rio de Janeiro: Lacerda Editores, 1999.

LIMA, Maria Regina Soares de. A política externa brasileira e os desafios da cooperação SulSul. Rev. bras. polít. int., Brasília, v. 48, n. 1, 2005. Disponível em: <http://www.scielo.br/ scielo.php? script $=$ sci_arttext $\&$ pid $=S 0034-73292005000100002 \& \operatorname{lng}=\& \mathrm{nrm}=\mathrm{iso}>$. Acesso em: 02 2008. doi: 10.1590/S0034-73292005000100002.

McCAIN, John. "An enduring peace built on freedom”. Foreign Affairs on-line [http://www. foreignaffairs.org/20071101faessay86602/john-mccain/an-enduring-peace-built-on-freedom. html] Disponibilidade: 1/3/2008.

OBAMA, Barack. "Renewing American Leadership". Foreign Affairs on line [http://www. foreignaffairs.org/20070701faessay86401/barack-obama/renewing-americanleadership.html] Disponibilidade: $1 / 0 / 2008$.

PECEQUILO, Cristina Soreanu. A Politica Externa dos EUA: Continuidade ou Mudança?. Porto Alegre: Ed. UFRGS, 2005, 2 ${ }^{\text {a }}$ Ed. ampliada e atualizada.

PECEQUILO, Cristina Soreanu e GOMES, Lucyana Sposito. Oportunidades e desafios: as relações bilaterais Brasil e EUA (1993/2004). Cena Internacional, 6(2), 2004.

RICE, Condoleeza. Remarks at the Memorial Museum ofJuscelino Kubitschek. Brasilia, Brazil, April 27, 2005. http://www.state.gov/secretary/rm/2005/45276.htm. Disponibilidade: $1 / 2 / 2008$. 
RICE, Condoleeza. Remarks with Brazilian Foreign Minister Celso Amorim. Itamaraty. Brasilia, Brazil, March13,2008. www.state.gov/secretary/rm/2008/03/102228.htm. Disponibilidade: $14 / 3 / 2008$.

SILVA, Luis Inácio Lula da, AMORIM, Celso e GUIMARÃES, Samuel Pinheiro. A Política Externa do Brasil. Brasília: IPRI/FUNAG, 2003.

VIGEVANI, Tullo e OLIVEIRA, Marcelo Fernandes de. "A política externa no governo FHC: a busca de autonomia pela integração". Revista Tempo Social, 15 (2) 2003.

VIGEVANI, Tullo e CEPALUNI, Gabriel. "A política externa de Lula da Silva: a autonomia pela diversificação”. Contexto Internacional, 29 (2), 2007.

VIZENTINI, Paulo. Relações Internacionais do Brasil: de Vargas a Lula. São Paulo. Fundação Perseu Abramo. 2003.

VIZENTINI, Paulo. O G-3 e o G-20: o Brasil e as novas coalizões internacionais" in ALTEMANI, Henrique \& LESSA, Antonio Carlos (orgs). Relaçôes internacionais do Brasiltemas e agendas. Vol. 2. São Paulo: Saraiva, 2006. p. 159-193.

\section{Resumo}

Avaliando a primeira década do século XXI, a política externa do Brasil tem passado por uma evolução significativa caracterizada por uma posição internacional e projeção de poder assertiva, dinamizando parcerias estratégicas com países desenvolvidos e emergentes. 0 objetivo deste artigo é analisar as prioridades desta agenda e os potenciais relacionados a estes esforços de cooperação bi e multilateral horizontal e vertical.

\section{Abstract}

Considering the first decade of the $21^{\text {st }}$ century, Brazil's foreign policy has been undergoing a significant evolution characterized by an assertive international stance and power projection, promoting an update and enlargement of strategic partnerships with developed and emerging countries. The aim of this paper is to analyze the main tenets of this agenda and the potentials linked to these efforts of horizontal and vertical bi and multilateral cooperation.

Palavras-Chave: Política Externa Brasileira, Parcerias Estratégicas, Cooperação Horizontal, Cooperação Vertical.

Key words: Brazilian Foreign Policy, Strategic Partnerships, Horizontal Cooperation, Vertical Cooperation. 